\title{
Curcumin regulates intracellular calcium release and inhibits oxidative stress parameters, VEGF, and caspase-3/-9 levels in human retinal pigment epithelium cells
}

\author{
H Bardak ${ }^{1}$, AC Ŭguz ${ }^{2,3}$, Y Bardak ${ }^{1}$ \\ ${ }^{1}$ Department of Ophthalmology, Haydarpasa Numune Research and Training Hospital, Istanbul, Turkey \\ ${ }^{2}$ Faculty of Medicine, Department of Biophysics, Süleyman Demirel University, Isparta, Turkey \\ ${ }^{3}$ Neuroscience Research Center, Süleyman Demirel University, Isparta, Turkey
}

Received: April 15, 2017

Accepted: October 9, 2017

In this study, we aimed to observe whether curcumin (cur), a polyphenolic compound derived from the dietary spice turmeric, a yellow substance obtained from the root of the plant Curcuma longa Linn, has any protective effect against blue light irradiation in human retinal pigment epithelium (ARPE-19) cells. For this purpose, we evaluated the intracellular calcium release mechanism, poly ADP ribose polymerase (PARP), procaspase-3/-9 protein expression levels, caspase activation, and reactive oxygen species levels. ARPE-19 cells were divided into four main groups, such as control, cur, blue light, and cur + blue light. Results were evaluated by KruskalWallis and Mann-Whitney $U$ tests as post hoc tests. The cells in cur and cur + blue light samples were incubated with $20 \mu \mathrm{M}$ cur. Blue light exposure was performed for $24 \mathrm{~h}$ in an incubator. Lipid peroxidation and cytosolicfree $\mathrm{Ca}^{2+}\left[\mathrm{Ca}^{2+}\right]_{\mathrm{i}}$ concentrations were higher in the blue light exposure samples than in the control samples; however, their levels were determined as significantly lower in the cur and cur + blue light exposure samples than in the blue light samples alone. PARP and procaspase-3 levels were significantly higher in blue light samples. Cur administration significantly decreased PARP and procaspase-3 expression levels. Reduced glutathione and glutathione peroxidase values were lower in the blue light exposure samples, although they were higher in the cur and cur + blue light exposure samples. Caspase-3 and -9 activities were lower in the cur samples than in the blue light samples. Moreover, vascular endothelial growth factor (VEGF) levels were significantly higher in the blue light exposure samples. In conclusion, cur strongly induced regulatory effects on oxidative stress, intracellular $\mathrm{Ca}^{2+}$ levels, VEGF levels, PARP expression levels, and caspase-3 and -9 values in an experimental oxidative stress model in ARPE-19 cells.

Keywords: apoptosis, ARPE-19 cells, blue light damage, $\mathrm{Ca}^{2+}$ signaling, curcumin, oxidative stress

\section{Introduction}

All internal and external body surfaces are covered by epithelial tissues. These cell layers have various functions depending on their location, and many of these functions are controlled by calcium $\left(\mathrm{Ca}^{2+}\right)$ activity $(30,36)$. The retinal pigment epithelium (RPE) cells belong to this type, and play a key role in the pathophysiology of age-related macular degeneration (AMD). AMD is one of the leading causes of visual impairment and blindness in patients aged 65 and over not only in developing countries, but also

Corresponding author: Dr. A. Cihangir Uğuz; Department of Biophysics, School of Medicine, Süleyman Demirel University

Dogu Kampusu, Morfoloji Binasi, Isparta TR-32260, Turkey

Phone: +90 24621136 60; Fax: +90246237 11 65; E-mail: cihangiruguz@yahoo.com 
worldwide, the highest prevalence of AMD was described in European ancestry (28). The pigmented monolayer of retina and/or the RPE cell layer is the pigmented and polarized cell layer just outside the neurosensory system and forms part of the blood-retinal barrier (17). The RPE plays a crucial role in the maintenance (36) and protection of photoreceptors. The RPE is also responsible for absorbing light, regulating the nutrient uptake mechanism, ion transfer with water, and eliminating waste from the subretinal tissue, as well as secretion (39). Moreover, RPE cells contain many antioxidant enzymes, such as superoxide dismutase, heme oxygenase, and some enzymes involved in glutathione (GSH) synthesis (39).

As in other epithelial tissues, any local deformation of the RPE cell membrane will trigger a significant $\mathrm{Ca}^{2+}$ influx to the cytosol and increase intracellular $\mathrm{Ca}^{2+}\left(\left[\mathrm{Ca}^{2+}\right]_{\mathrm{i}}\right)$ $(1,13,14)$. This kind of damage in the cell membrane may also occur in clinical applications during surgical procedures. Furthermore, RPE cells are important in pathological conditions, such as excessive retinal tear secretions complication after photodynamic therapy (8), intravitreal injection of bevacizumab (7), or pegaptanib (32). $\mathrm{Ca}^{2+}$ signaling occurs as a result of intercellular transient waves, and is also linked to the initial stages of many physiological processes, such as fertilization, cell death, and wound healing. An excessive amount of $\mathrm{Ca}^{2+}$ influx will result in cell death (35). Mechanical stimulation of the cells also causes cell death and thus initiates $\mathrm{Ca}^{2+}$ waves that generate $\mathrm{Ca}^{2+}$ gradients, which play an important role in cell migration (30).

The visible spectrum's components, which trigger many types of cellular dysfunction and cell death mechanisms, can be absorbed by biological chromophores (formed by rhodopsin, which intermediates in the photoreceptor's outer segment) in human RPE cells. The blue region of the light spectrum (400-500 nm) has high energy and can affect the function of several blue-light-absorbing enzymes by deeply infiltrating cells and organelles (23). Moreover, this region of the spectrum has been reported to be a damaging component for retinal tissues. Blue light has been shown to induce the production of reactive oxygen species (ROS) in RPE cells (18), triggering apoptosis and causing increased $\left[\mathrm{Ca}^{2+}\right]_{i}$ levels (3).

Oxidative stress presents an unbalanced situation between oxidants and antioxidants -in favor of oxidants - and can occur in all physiological conditions (19). If the biological system's scavenging mechanisms are strong enough to detoxify oxidant agents, the living organism will survive. However, any deficiency in the scavenging mechanisms will have detrimental effects on the cell. It has been well-documented in the literature that the antioxidant defense system declines with age (19). Increased ROS levels initiate a cyclic membrane depolarization that causes intolerable amount of ion influx to the cytosol (3). This cellular process terminates with apoptosis $(11,12)$.

Cur is an active component of the dietary spice turmeric, and is extracted from the rhizomes of Curcuma longa, a member of the ginger family. It has been widely used in traditional medicine due to its antioxidant (40), anti-inflammatory (4), antiproliferative (37), and other therapeutic properties. Cur has also been shown to have protective effects in retinal disease by reducing both inflammation and oxidative damage (37). Due to its strong antioxidant properties, cur has gained the attention of specialists for various treatments. Based on literature research, it can be argued that even if cur is able to protect ARPE-19 cells against oxidative stress, it is unclear which detailed mechanism is responsible for this ability. 
The aim of this study is to provide a deeper understanding of the molecular mechanisms responsible for the effect of cur on the in vitro response of RPE cells to a non-lethal dose of blue-light-induced cytotoxicity by evaluating intracellular $\mathrm{Ca}^{2+}$ dynamics, vascular endothelial growth factor (VEGF) levels, apoptosis, caspase-3 and -9 levels, and oxidative stress parameters.

\section{Materials and Methods}

\section{Chemicals}

All chemicals (cumenehydroperoxide, $\mathrm{KOH}, \mathrm{NaOH}$, thiobarbituric acid, 1,1,3,3tetraethoxypropane, 5,5-dithiobis-2 nitrobenzoic acid, tris-hydroxymethyl-aminomethane, GSH, butylhydroxytoluol, Triton X-100 and ethylene glycol-bis [2-aminoethyl-ether]-N, N,N,N-tetraacetic acid [EGTA]) were obtained from Sigma-Aldrich (St. Louis, MO, USA) and all organic solvents (n-hexane, ethyl alcohol) were purchased from Merck (Darmstadt, Germany). Fura-2 acetoxymethyl ester was purchased from Invitrogen (Carlsbad, CA, USA). All reagents were analytical grade. All reagents except the phosphate buffers were prepared daily and stored at $+4{ }^{\circ} \mathrm{C}$. Reagents were equilibrated at room temperature for half an hour before an analysis was initiated or reagent containers were refilled. APOPercentage ${ }^{\mathrm{TM}}$ assay kit was purchased from Biocolor (Belfast, Northern Ireland). Each experiment was repeated at least six times.

\section{Study groups}

Control group: ARPE-19 cells were incubated for $24 \mathrm{~h}$ in their medium $\left(37^{\circ} \mathrm{C}\right.$ and $5 \% \mathrm{CO}_{2}$ ).

Blue light group: ARPE-19 cells were exposed to blue light irradiation for $24 \mathrm{~h}$, details previously determined elsewhere (3).

Cur group: ARPE-19 cells were incubated with $20 \mu \mathrm{M}$ cur for $3 \mathrm{~h}$, details previously determined elsewhere (16). Cur was dissolved in dimethyl sulfoxide (40).

Cur + blue light group: ARPE-19 cells were incubated with $20 \mu \mathrm{M}$ for $3 \mathrm{~h}$ with cur and washed with $1 \times$ phosphate-buffered solution (PBS) then exposed to blue light for $24 \mathrm{~h} \mathrm{(3).}$

\section{Cell culture}

Human retinal pigment epithelium cell line (ARPE-19) (ATCC, USA) (6) was grown in a mixture of a medium containing 1:1 ratio of Dulbecco's modified eagle medium and Ham's F12 medium supplemented with 10\% fetal bovine serum (Biochrom, Germany) and 1\% penicillin-streptomycin combination (Biochrom, Germany) according to the procedure of the supplier's instruction. Cells were used at passages 3-10. The cell culture was performed at $37{ }^{\circ} \mathrm{C}$ in a humidified incubator with $5 \% \mathrm{CO}_{2}$.

\section{Exposure of ARPE-19 cells to blue light}

Illumination of the blue light was produced by a LED-based system generating $405 \mathrm{~nm}$ blue light at an output power of $1 \mathrm{Mw} / \mathrm{cm}^{2}$ (Conrad Electronic GmBh, Germany). LED arrays were developed with the help of the Department of Electronics and Communication, Engineering Faculty of Süleyman Demirel University. Cells were excited in their own flasks for different durations as described in the "Study groups" section (TPP, Trasadingen, Germany). 
Calcium $\left(\left[\mathrm{Ca}^{2+}\right]_{i}\right)$ determination by fluorescent dye

Cells were loaded with Fura-2 by incubation with $4 \mu \mathrm{M}$ Fura-2 acetoxymethyl ester (Fura-2/AM) for $30 \mathrm{~min}$ at room temperature according to a procedure published elsewhere (35). Once loaded, the cells were washed and gently resuspended in Na-HEPES solution containing (in $\mathrm{mM}$ ): $140 \mathrm{NaCl}, 4.7 \mathrm{KCl}, 1.2 \mathrm{CaCl}_{2}, 1.1 \mathrm{MgCl}_{2}$, 10 glucose, and 10 HEPES ( $\mathrm{pH}$ 7.4). The four groups were exposed to $\mathrm{H}_{2} \mathrm{O}_{2}$ for stimulating $\left(\left[\mathrm{Ca}^{2+}\right]_{\mathrm{i}}\right)$ release. Fluorescence was recorded from $2 \mathrm{ml}$ aliquots of magnetically stirred cellular suspension $\left(2 \times 10^{6}\right.$ cells $\left./ \mathrm{ml}\right)$ at $37{ }^{\circ} \mathrm{C}$ using a spectrofluorometer (Cary Eclipse, Varian Inc, Sydney, Australia) with excitation wavelengths of 340 and $380 \mathrm{nM}$ and emission at $505 \mathrm{nM}$. Changes in $\left[\mathrm{Ca}^{2+}\right]_{\mathrm{i}}$ were monitored using the Fura-2 $340 / 380 \mathrm{nM}$ fluorescence ratio and were calibrated according to the method of Grynkiewicz et al. (10). $\mathrm{Ca}^{2+}$ release was estimated using the integral of the rise in $\left[\mathrm{Ca}^{2+}\right]_{\mathrm{i}}$ for $80 \mathrm{~s}$ after addition of $\mathrm{H}_{2} \mathrm{O}_{2}(2) . \mathrm{Ca}^{2+}$ release is expressed in $\mathrm{nM}$ taking a sample every second $(\mathrm{nM} / \mathrm{s})$ as previously described (35).

\section{Measurement of ROS-sensitive fluorescence}

Cells were loaded with $10 \mu \mathrm{M}$ dihydrorhodamine- 123 by incubation at $37^{\circ} \mathrm{C}$ for $30 \mathrm{~min}$ as previously described (33). This probe is a non-fluorescent cell-permeable compound. Once inside the cell, it turns fluorescent upon oxidation to yield rhodamine-123 (Rh-123), fluorescence being proportional to ROS generation. The fluorescence intensity of Rh-123 was measured in an automatic microplate reader (Tecan Infinite M200, Austria). Excitation was set at $488 \mathrm{~nm}$ and emission at $543 \mathrm{~nm}$. Treatments were carried out in triplicates. Data are presented as fold increase over the pretreatment level (experimental/control).

\section{Western blot analysis}

ARPE-19 cells were harvested and pooled in $100 \mu \mathrm{l}$ of a lysis buffer (Bio-Rad, USA). Cell lysates were centrifuged at $15,000 \mathrm{rpm}$ for $20 \mathrm{~min}$ at $4{ }^{\circ} \mathrm{C}$, and the supernatants were collected. We calibrated the protein concentrations in equal amounts. Later, they were separated by electrophoresis on a $12.5 \%$ Sodium dodecyl sulfate-polyacrylamide gel and electrophoretically transferred to a nitrocellulose membrane (Bio-Rad). After incubating with blocking buffer with a $3 \%$ bovine serum albumin solution, the membrane was incubated overnight at $4{ }^{\circ} \mathrm{C}$. Antibodies used in the Western blot assay included an anti-poly ADP ribose polymerase (PARP) (\#9532, 1:1000 diluted) and pro-caspase -3 and -9 antibody (\#9665, 1:1000 diluted and \#9508,1:1000 diluted, respectively) (Cell Signaling, Danvers, MA, USA); $\beta$-actin (\#3700, 1:1000 diluted) served as an internal control. Obtained bands were visualized using ECL Western HRP Substrate (Millipore Luminate Forte, USA), and visualization was achieved through Syngene G:BOX Gel Imagination System (UK) and normalized against $\beta$-actin protein. The data are presented as relative density (fold increase) over the pretreatment level (experimental/control).

\section{Determination of VEGF levels}

ARPE-19 cells $\left(3 \times 10^{4}\right.$ cells per well $)$ in $100 \mu$ of cell culture medium were plated in 96 well plates at a confluency of $90 \%$. Subsequently, the culture medium was refreshed, and the cells were incubated/stimulated in the presence/absence of cur or blue light.

After the prescribed incubation time $\left(37{ }^{\circ} \mathrm{C}\right.$ in $\left.5 \% \mathrm{CO}_{2}\right)$, media was collected and assessed for levels of VEGF by ELISA kit (Sigma Aldrich, Saint Louis, MO, USA) according to the manufacturer's protocol. The $R^{2}$ was determined as 0.999 in the curved line. 
Measurement of lipid peroxidation (LP) level

LP levels in the ARPE-19 cell lines were measured with the thiobarbituric acid reaction by the method of Placer et al. (26). The quantification of thiobarbituric acid reactive substances was determined by comparing the absorption with the standard curve of malondialdehyde equivalents generated by acid catalyzed hydrolysis of 1,1,3,3 tetramethoxypropane.

Reduced GSH, glutathione peroxidase (GSH-Px), and protein assay

The GSH content of the ARPE-19 cells was measured at $412 \mathrm{nM}$ using the method of Sedlak and Lindsay (31). GSH-Px activities of ARPE-19 cells were measured spectrophotometrically at $37^{\circ} \mathrm{C}$ and $412 \mathrm{nM}$ according to the Lawrence and Burk method (20). The protein content in the ARPE-19 cells was measured by method of Lowry et al. (24) with bovine serum albumin used as the standard.

\section{Measurement of mitochondrial membrane potential}

Cells were incubated with $1 \mu \mathrm{M} \mathrm{JC}-1$ for $15 \mathrm{~min}$ at $37^{\circ} \mathrm{C}$ as previously described (33). The cationic dye, JC-1, exhibits potential-dependent accumulation in mitochondria. It indicates mitochondria depolarization by a decrease in the red-to-green fluorescence intensity ratio. After incubation with $\mathrm{JC}-1$, the dye was removed, and the cells were washed in PBS. The green JC-1 signal was measured at an excitation wavelength of $485 \mathrm{~nm}$ and an emission wavelength of $535 \mathrm{~nm}$, whereas the red signal was detected at an excitation wavelength of $540 \mathrm{~nm}$ and an emission wavelength of $590 \mathrm{~nm}$. Fluorescence changes were analyzed using a fluorescence spectrophotometer (Tecan Infinite M200). Treatments were carried out in triplicates. Data are presented as emission ratios $(590 / 535)$. Changes in mitochondrial membrane potential were quantified as the integral of the decrease in JC-1 fluorescence ratio.

\section{Apoptosis assay}

The APOPercentage ${ }^{\mathrm{TM}}$ assay (Biocolor Ltd., Belfast, Northern Ireland) was performed according to the instructions provided by Biocolor Ltd. and as also described elsewhere (34). The APOPercentage ${ }^{\mathrm{TM}}$ assay is a dye-uptake assay, which stains only the apoptotic cells with a red dye. When the membrane of apoptotic cell loses its asymmetry, the APOPercentage dye is actively transported into cells, staining apoptotic cells red, thus allowing detection of apoptosis by spectrophotometer (34).

\section{Assay for caspase activities}

To determine caspase- 3 and -9 activities, ARPE-19 cells were sonicated and cell lysates were incubated with $2 \mathrm{ml}$ of substrate solution [20 mm HEPES (pH 7.4), 2 mM EDTA, $0.1 \%$ CHAPS, $5 \mathrm{mM}$ DTT, and $8.25 \mu \mathrm{M}$ of caspase substrate] for $1 \mathrm{~h}$ at $37{ }^{\circ} \mathrm{C}$ as previously described (35). The activities of caspase- 3 and -9 were calculated from the cleavage of the respective specific fluorogenic substrate (AC-DEVD-AMC for caspase-3 and AC-LEHDAMC for caspase-9). Substrate cleavage was measured with a fluorescence spectrophotometer with an excitation wavelength of $360 \mathrm{~nm}$ and an emission wavelength of $460 \mathrm{~nm}$. Preliminary experiments had confirmed that caspase- 3 or -9 substrate cleaving had not been detected in the absence of the inhibitors of caspase-3 (DEVD-CMK) or -9 (z-LEHDFMK). The data were calculated as fluorescence units per milligram of protein. 
Statistical analysis

Data are expressed as means \pm SD of the number of determinations. Statistical significance was analyzed using SPSS program (9.05, SPSS, Chicago, IL). To compare the effects of different treatments, statistical significance was calculated by Kruskal-Wallis and Mann-Whitney $U$ tests and post hoc tests. $p<0.05$ was considered to indicate a statistically significant difference.

\section{Results}

Effects of cur and blue light on $\left[\mathrm{Ca}^{2+}\right]_{i}$ release in ARPE-19 cells

Effects of cur on $\left[\mathrm{Ca}^{2+}\right]_{\mathrm{i}}$ release in the ARPE-19 cells are shown in Fig. 1A. We did not determine any statistical significance between cur and control samples. Exposure to blue light markedly increased $\left[\mathrm{Ca}^{2+}\right]_{\mathrm{i}}$ levels compared with control and cur samples. The areas under curve presented as bar charts (Fig. 1B) reflect $\left[\mathrm{Ca}^{2+}\right]_{i}$ concentrations from $\mathrm{H}_{2} \mathrm{O}_{2}$ stimulated ARPE-19 cells. Blue light exposure increased $\left[\mathrm{Ca}^{2+}\right]_{\mathrm{i}}$ levels. Cur incubation significantly decreased $\left[\mathrm{Ca}^{2+}\right]_{\mathrm{i}}$ levels $(p<0.001)$. Our findings suggest that cur incubation regulates the $\left[\mathrm{Ca}^{2+}\right]_{\mathrm{i}}$ signaling mechanism.

\section{Effects of cur and blue light on apoptosis levels in ARPE-19 cells}

The effects of cur and blue light on apoptosis levels in ARPE-19 cells are shown in Fig. 2. The mean apoptosis levels increased in blue light and cur + blue light samples compared with control samples. The apoptosis levels were significantly lower in the control and cur $(p<0.001)$ groups compared with the blue light samples. However, apoptosis levels were significantly decreased in cur + blue light samples $(p<0.001)$ compared with blue light samples. Hence, we observed the protective effects of cur on apoptosis levels of blue light triggered oxidative stress models in ARPE-19 cells.

Effects of cur and blue light on LP, reduced GSH, GSH-Px, and ROS values in ARPE-19 cells LP, GSH, and GSH-Px values obtained from the ARPE-19 cells in the four groups are shown in Table I. The results indicated that LP levels were markedly $(p<0.001)$ higher in blue light samples compared with the control samples. Moreover, GSH-Px activity and GSH levels were statistically $(p<0.001)$ lower in the blue light samples compared with the control samples. However, the LP levels were significantly lower in the cur $(p<0.001)$ and cur + blue light $(p<0.001)$ samples compared with the blue light only samples.

ROS levels were determined with fluorescent dye. The ROS levels obtained from the study groups are shown in Table I. The results indicated that ROS levels were significantly $(p<0.001)$ higher in blue light samples compared with the control samples. Moreover, ROS levels were statistically $(p<0.001)$ lower in the cur + blue light samples compared with blue light samples. Our results strongly suggest the scavenging effects of Cur by inhibiting ROS and LP levels as well as increasing GSH and GHS-Px levels.

Effects of cur and blue light on caspase-3 and -9 activity levels in ARPE-19 cells

Caspase -3 and -9 activity levels are shown in Fig. 3. The caspase-3 activity levels in control and blue light samples were significantly higher than in cur samples $(p<0.05$ and $p<0.001$, respectively). Cur incubation decreased caspase- 3 activation in cur + blue light samples. It 

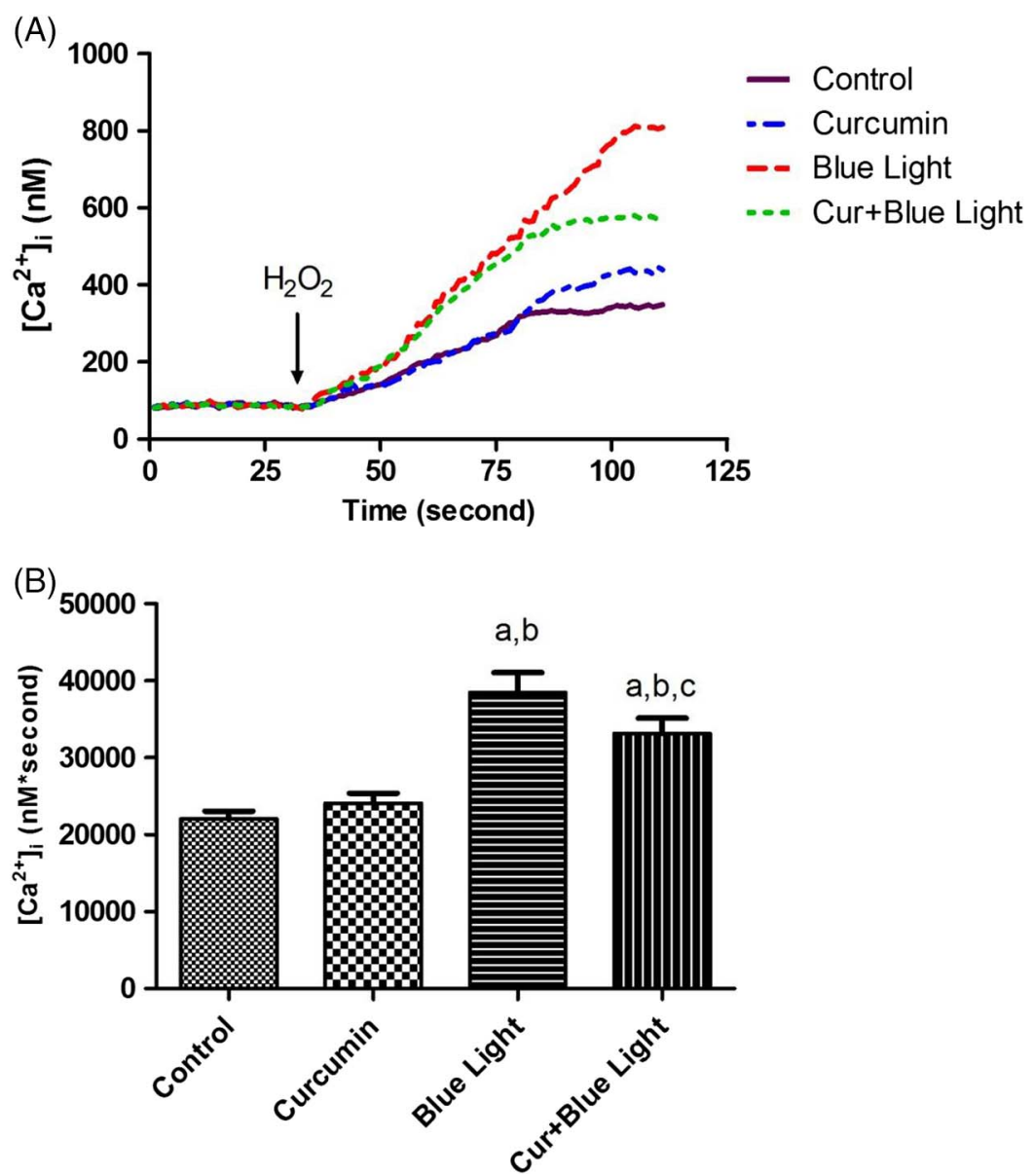

Fig. 1. (A) Calcium release from ARPE-19 cells exposed to curcumin (cur) and hydrogen peroxide Blue Light following stimulation with $\mathrm{H}_{2} \mathrm{O}_{2}$. Original time course chart recordings showing $\left[\mathrm{Ca}^{2+}\right]_{\mathrm{i}}$ transients in ARPE-19 cells. (B) Bar charts showing areas under calcium signaling traces, mean $\pm \mathrm{SD}$ data for $\left[\mathrm{Ca}^{2+}\right]_{\mathrm{i}}$ from $\mathrm{H}_{2} \mathrm{O}_{2}$-stimulated ARPE-19 cells ( $n=6$ for each sample). Note the significant elevation in $\left[\mathrm{Ca}^{2+}\right]_{\mathrm{i}}$ for ARPE-19 cells compared with control. ${ }^{\mathrm{a}} p<0.001$ versus control samples; ${ }^{\mathrm{b}} p<0.001$ versus cur samples; ${ }^{\mathrm{c}} p<0.001$ versus blue light samples

was clearly understood that caspase-3 activity level in cur + blue light samples was significantly lower than in blue light samples $(p<0.05)$.

The caspase-9 levels in blue light and cur + blue light samples were significantly higher than in control samples $(p<0.001)$. Caspase- 9 activity levels did not show any statistically significant difference between control samples and cur samples. We observed that cur incubation strongly inhibits caspase-3 and -9 activity levels, which is also supported by our apoptosis findings, a key finding in cell death mechanism.

\section{Effects of cur and blue light on VEGF levels in ARPE-19 cells}

The VEGF levels are shown in Fig. 4. VEGF levels in the cur + blue light samples were significantly lower than those in blue light samples $(p<0.001)$. In addition, it was determined 




Fig. 2. Effects of curcumin (Cur) and blue light on apoptosis levels in ARPE-19 cells (mean $\pm \mathrm{SD} ; n=8$ ). The values are expressed as fold increase over the control level (experimental/control). ${ }^{\mathrm{a}} p<0.001$ versus the control samples; ${ }^{\mathrm{b}} p<0.001$ versus the cur samples; ${ }^{c} p<0.001$ versus the blue light samples

Table I. The effects of curcumin (cur) and blue light on lipid peroxidation (LP), glutathione peroxidase (GSH-Px), reduced glutathione $(\mathrm{GSH})$ values, and reactive oxygen species levels (ROS) in ARPE-19 cells (mean \pm SD) (optical density, OD)

\begin{tabular}{|l|c|c|c|c|}
\hline Parameters/groups & Control & Curcumin & Blue light & Curcumin + blue light \\
\hline LP $(\mu \mathrm{mol} / \mathrm{g} p r o t)$ & $12.41 \pm 0.95$ & $11.13 \pm 1.67^{\mathrm{a}}$ & $20.17 \pm 1.85^{\mathrm{a}, \mathrm{b}}$ & $13.76 \pm 1.70^{\mathrm{a}, \mathrm{b}, \mathrm{c}}$ \\
\hline GSH $(\mu \mathrm{mol} / \mathrm{g}$ prot$)$ & $8.12 \pm 0.43$ & $10.16 \pm 0.74^{\mathrm{a}}$ & $5.01 \pm 0.52^{\mathrm{a}, \mathrm{b}}$ & $8.12 \pm 0.77^{\mathrm{b}, \mathrm{c}}$ \\
\hline GSH-Px $(\mathrm{IU} / \mathrm{mg}$ prot$)$ & $13.25 \pm 0.89$ & $14.12 \pm 0.75^{\mathrm{a}}$ & $12.49 \pm 0.89^{\mathrm{a}, \mathrm{b}}$ & $14.89 \pm 1.49^{\mathrm{a}, \mathrm{c}}$ \\
\hline ROS $(\mathrm{OD})$ & $43,879 \pm 1,867.5$ & $44,021 \pm 1,034.52$ & $72,658 \pm 1,652.74^{\mathrm{a}, \mathrm{b}}$ & $63,124 \pm 1,018.24^{\mathrm{a}, \mathrm{b}, \mathrm{c}}$ \\
\hline
\end{tabular}

Fig. 3. Effects of curcumin (cur) and blue light on caspase- 3 and -9 in ARPE-19 cells $($ mean $\pm \mathrm{SD} ; n=8)$. The values are expressed as fold increase over the control level (experimental/control). ${ }^{\mathrm{a}} p<0.05$ versus the control samples; ${ }^{b} p<0.001$ versus the control samples; ${ }^{\mathrm{c}} p<0.001$ versus the cur samples; ${ }^{\mathrm{d}} p<0.05$ versus the blue light samples 


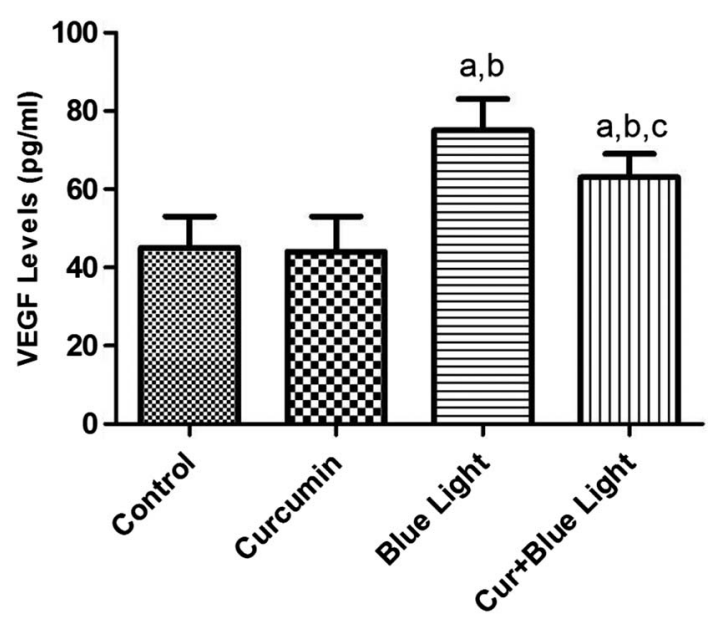

Fig. 4. Effects of curcumin (cur) and blue light on VEGF levels in ARPE-19 cells (mean \pm SD; $n=8)$. The values are expressed as $\mathrm{pg} / \mathrm{ml}$.

${ }^{\mathrm{a}} p<0.001$ versus the control samples;

${ }^{\mathrm{b}} p<0.001$ versus the cur samples; ${ }^{c} p<0.001$ versus the blue light samples

that the VEGF levels in the cur samples were significantly lower than those in the blue light and cur + blue light samples $(p<0.001)$. Hence, we observed the protective role of cur incubation against blue light-triggered VEGF increase.

\section{Effects of cur and blue light on mitochondrial depolarization levels in ARPE-19 cells} The mitochondrial depolarization levels are shown in Fig. 5. Control samples of mitochondrial depolarization levels were determined to be lower than in cur + blue light samples $(p<0.001)$. Mitochondrial depolarization levels in the cur and cur + blue light samples were significantly lower than those in blue light samples $(p<0.001)$. Moreover, it was determined that the mitochondrial depolarization levels in the cur samples had no significant changes compared with control samples. We observed that cur has a regulatory role in mitochondrial activity.

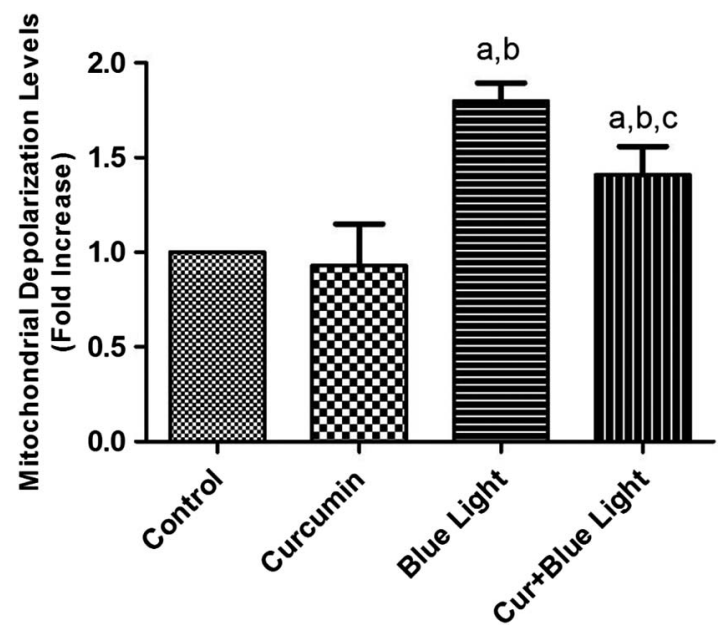

Fig. 5. Effects of curcumin (cur) and blue light on mitochondrial depolarization levels in ARPE-19 cells (mean $\pm \mathrm{SD} ; n=8$ ). The values are expressed as fold increase over the control level (experimental/control). ${ }^{\mathrm{a}} p<0.001$ versus the control samples; ${ }^{\mathrm{b}} p<0.001$ versus the cur samples; ${ }^{c} p<0.001$ versus the blue light samples 
Effects of cur and blue light on PARP and pro-caspase-3 / -9 expression levels in ARPE-19 cells

The PARP and procaspase-3/-9 expression levels are shown in Fig. 6. PARP expression levels were significantly higher in blue light irradiation samples $(p<0.001)$. However, PARP levels were significantly decreased in cur and cur + blue light irradiation samples. Procaspase-3 and -9 levels are shown in Fig. 6. Procaspase-3 and -9 levels were determined significantly decreased in blue light samples. Cur significantly increased procaspase-3 and -9 levels.

\section{Discussion}

The ARPE-19 cell line is an important experimental study model of human RPE despite its certain limitations. Our manuscript presents the first research on intracellular $\mathrm{Ca}^{2+}$ signaling, oxidative stress parameters, and their relation to VEGF levels in RPE cells. To the best of our knowledge, there is currently no documented research in the literature that has evaluated VEGF, $\mathrm{Ca}^{2+}$ signaling, ROS, and caspase levels under one study topic. The most important finding of the current research is that VEGF levels, intracellular $\mathrm{Ca}^{2+}$ release, oxidative stress parameters, and mitochondrial depolarization levels were increased by blue light damage. After blue light exposure, the damaging stimulus is transformed into an intracellular death signal, which is then transmitted to downstream effectors, such as transcription factor activator protein-1 (AP-1) (38). Grimm et al. (9) observed severe retinal damage, such as distinct lesions and completely inhibited metabolic rhodopsin regeneration with photoreversal bleaching in Rpe $65^{-/-}$mice. However, they did not determine any negative effect from green light exposure. Our results are consistent with the results described above. We also observed elevated apoptosis, oxidative stress parameters, and caspase- 3 and -9 values in our experimental model. Blue light irradiation significantly increased apoptosis levels in ARPE19 cells. However, the damaging effect of blue light irradiation can easily be reversed by incubating cells with cur prior to blue light exposure.

Neovascularization and vascular leakage are major causes of visual loss in retinaoriginated vascular disorders, as well as AMD (3). In neovascular AMD, cellular dysfunction of RPE is associated with the production of VEGF, which is an important component of angiogenesis. According to Ma et al. (25), experimentally induced VEGF overexpression in RPE is sufficient to induce choroidal neovascularization. In addition to stress conditions like hypoxia, some growth factors, inflammatory cytokines, and upstream mechanisms or stimuli can also increase VEGF expression levels (25). In this study, we first showed that blue light can directly stimulate ARPE-19 cells to secrete VEGF. We determined that blue light exposure significantly elevated VEGF levels compared with control and cur samples.

Chronic inflammation exerts adverse cellular effects through depletion of antioxidants against excessive production of free radicals. Inflammation is the key mediator of several common diseases in the eye. In this study, we determined increased ROS, LP levels, and decreased GSH and GSH-Px levels in blue light samples. Previously, Argun et al. (3) determined similar results. However, preincubation with cur significantly decreased LP and ROS levels and increased GSH and GSH-Px levels. Several studies have implicated intracellular ROS signaling in apoptosis, although a direct connection between apoptosis and increased levels of $\left[\mathrm{Ca}^{2+}\right]_{\mathrm{i}}$ with preincubation of cur in blue light exposure has not been established $(21,22)$. 


$$
\begin{array}{llll}
\text { Control Curcumin } & \begin{array}{l}
\text { Blue } \\
\text { Light }
\end{array} & \begin{array}{l}
\text { Curcumin + } \\
\text { Blue Light }
\end{array}
\end{array}
$$

$120 \mathrm{kDa}$

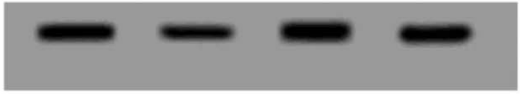

PARP

50 kDa

$30 \mathrm{kDa}$

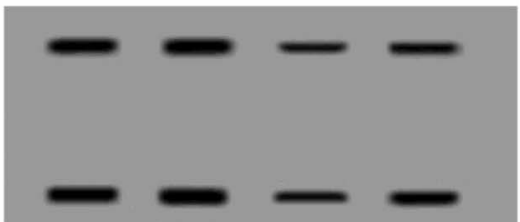

Procaspase-9

$42 \mathrm{kDa}$
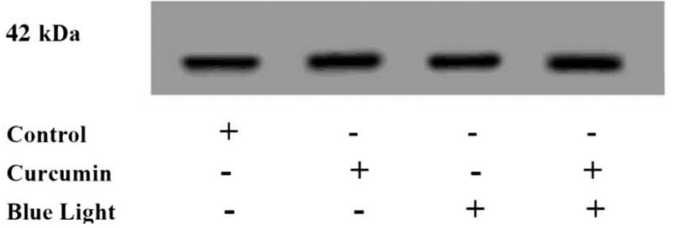

$\infty$ Caspase-3 $\quad \infty$ Caspase-9
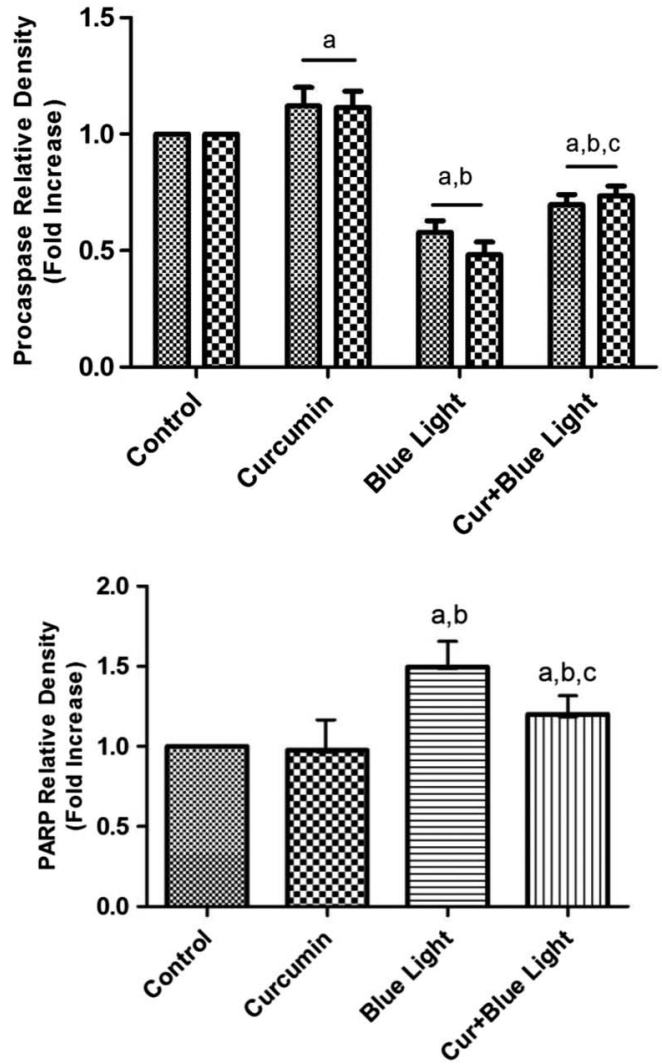

\section{$\beta$-actin}

Procaspase-3

( 
In the current cell culture study, we showed that blue light elevated $\left[\mathrm{Ca}^{2+}\right]_{\mathrm{i}}$ levels by increasing oxidative stress parameters and ROS levels, whereas cur supplementation provided a cell survival advantage against increased levels of $\left[\mathrm{Ca}^{2+}\right]_{\mathrm{i}}$. Although intracellular $\left[\mathrm{Ca}^{2+}\right]_{\mathrm{i}}$ has been presented as one of the key regulators of cell survival, this cation can also trigger apoptosis in response to many pathological conditions. Apoptosis, or programmed cell death mechanism, is mediated by specific proteinases, called caspases. Two major pathways are responsible for apoptotic cascades (29). One of these pathways involves death receptors, and is marked by Fas-mediated activation; the other pathway involves stress-mediated caspase activation. The latter pathway is a mitochondriaoriginated cascade and membrane depolarization levels are the key players. Here, we observed altered mitochondrial depolarization levels in the blue light exposure. This could be due to the oxidant agents, most of which originated from mitochondria. It has been previously reported that a sudden and intolerable prolonged alteration in $\left[\mathrm{Ca}^{2+}\right]_{\mathrm{i}}$ levels triggers a mitochondrion-originated apoptotic pathway (5) and initiate endoplasmic reticulum stress, which later leads to significant increase in apoptotic cell death ratio (27). Vainio et al. (36) have recently demonstrated that in RPE, an easily induced and repeatable $\mathrm{Ca}^{2+}$ wave could be produced by mechanical stimulation. This provides an experimental tool to study $\mathrm{Ca}^{2+}$ activity in the epithelial monolayer. Our Western blot results are also compatible with spectrofluorometric findings that procaspase- 3 and -9 levels, which would be subsequently converted to active caspase- 3 and -9 , were determined to be low. Caspase activation includes often oligomerization of procaspases, and is followed by cleavage into bigger or smaller subunits. The bigger and smaller subunits are associated with each other to form an active heterodimer caspase. One of the key players of the apoptosis is PARP. PARP family members are involved in the DNA repair mechanisms and programmed cell death pathways. PARP inhibitors are attractive targets for preventing different types of diseases. One of the most important aims of this study was to observe whether cur has any protective effects against PARP expression levels after blue light irradiation. Western blot results clearly demonstrate that curcumin significantly inhibits PARP expression levels.

There are some controversial results in the literature. Hollborn et al. (15) observed toxic effects of cur in ARPE-19 cells. According to our findings, these toxic effects may be due to (may arise from) the long incubation period. Our results clearly show that in the short cur incubation time period, the action of the compound has regulatory effects. Our results indicate that collaborative interaction occurs between $\left[\mathrm{Ca}^{2+}\right]_{\mathrm{i}}$ signaling mechanisms and VEGF levels in ARPE-19 cells. It can be clearly seen that blue light exposure increased both VEGF and $\left[\mathrm{Ca}^{2+}\right]_{\mathrm{i}}$ levels in ARPE-19 cells. Future studies will be focused on this topic, particularly some specific ion channels such as transient receptor potential (TRP) channels.

In the current investigation, we have demonstrated that cur has protective effect against blue light-induced retinal cell damage and is able to delay oxidative stressmediated increases in $\left[\mathrm{Ca}^{2+}\right]_{\mathrm{i}}$ levels, PARP expression levels, apoptosis levels, and caspase activation in ARPE-19 cells. These findings may have therapeutic implications in light toxicity and related inflammatory diseases. We proposed that cur is able to reduce apoptotic cell death, which is mainly due to the mitochondrion-originated intracellular signaling pathways. These notable findings strongly underline the potential protective role of cur as a regulator of cellular signaling mechanisms of the life/death of retinal cells. 


\section{Authors' contribution}

HB, ACU, and YB formulated the hypothesis. HB and ACU were responsible for experiments. They were also responsible for writing the manuscript.

\section{Conflict of interest}

None of the authors have any conflicts to disclose. All authors approved the final version of the manuscript.

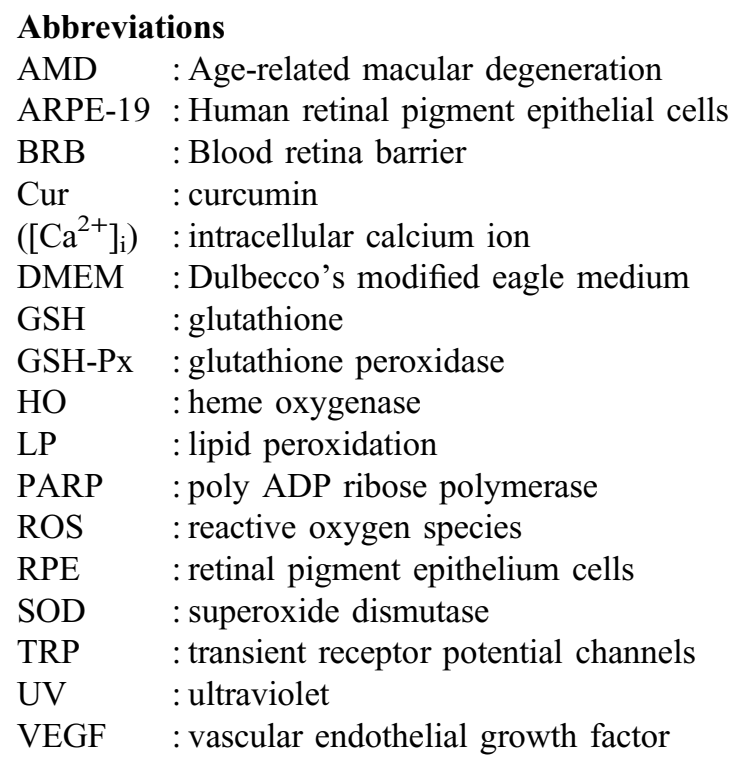

\section{REFERENCES}

1. Abu Khamidakh AE, Juuti-Uusitalo K, Larsson K, Skottman H, Hyttinen J: Intercellular Ca(2+) wave propagation in human retinal pigment epithelium cells induced by mechanical stimulation. Exp. Eye Res. 108, 129-139 (2013)

2. Altinkilic S, Naziroglu M, Uguz AC, Ozcankaya R: Fish oil and antipsychotic drug risperidone modulate oxidative stress in PC12 cell membranes through regulation of cytosolic calcium ion release and antioxidant system. J. Membr. Biol. 235, 211-218 (2010)

3. Argun M, Tok L, Uguz AC, Celik O, Tok OY, Naziroglu M: Melatonin and amfenac modulate calcium entry, apoptosis, and oxidative stress in ARPE-19 cell culture exposed to blue light irradiation ( $405 \mathrm{~nm}$ ). Eye 28, 752-760 (2014)

4. Belkacemi A, Doggui S, Dao L, Ramassamy C: Challenges associated with curcumin therapy in Alzheimer disease. Expert Rev. Mol. Med. 13, e34 (2011)

5. Demaurex N, Distelhorst C: Cell biology. Apoptosis - The calcium connection. Science 300, 65-67 (2003)

6. Dunn KC, Aotaki-Keen AE, Putkey FR, Hjelmeland LM: ARPE-19, a human retinal pigment epithelial cell line with differentiated properties. Exp. Eye Res. 62, 155-169 (1996)

7. Garg S, Brod R, Kim D, Lane RG, Maguire J, Fischer D: Retinal pigment epithelial tears after intravitreal bevacizumab injection for exudative age-related macular degeneration. Clin. Exp. Ophthalmol. 36, 252-256 (2008)

8. Gelisken F, Inhoffen W, Partsch M, Schneider U, Kreissig I: Retinal pigment epithelial tear after photodynamic therapy for choroidal neovascularization. Am. J. Ophthalmol. 131, 518-520 (2001)

9. Grimm C, Wenzel A, Williams T, Rol P, Hafezi F, Remé C: Rhodopsin-mediated blue-light damage to the rat retina: Effect of photoreversal of bleaching. Invest. Ophthalmol. Vis. Sci. 42, 497-505 (2001) 
10. Grynkiewicz G, Poenie M, Tsien RY: A new generation of $\mathrm{Ca}^{2+}$ indicators with greatly improved fluorescence properties. J. Biol. Chem. 260, 3440-3450 (1985)

11. Hajnoczky G, Csordas G: Calcium signalling: Fishing out molecules of mitochondrial calcium transport. Curr. Biol. 20, R888-R891 (2010)

12. Hajnoczky G, Saotome M, Csordas G, Weaver D, Yi M: Calcium signalling and mitochondrial motility. Novartis Found. Symp. 287, 105-117 (2007)

13. Hansen M, Boitano S, Dirksen ER, Sanderson MJ: Intercellular calcium signaling induced by extracellular adenosine 5'-triphosphate and mechanical stimulation in airway epithelial cells. J. Cell Sci. 106, 995-1004 (1993)

14. Himpens B, Stalmans $\mathrm{P}$, Gomez $\mathrm{P}$, Malfait M, Vereecke J: Intra- and intercellular $\mathrm{Ca}^{2+}$ signaling in retinal pigment epithelial cells during mechanical stimulation. FASEB J. 13, S63-S68 (1999)

15. Hollborn M, Chen R, Wiedemann P, Reichenbach A, Bringmann A, Kohen L: Cytotoxic effects of curcumin in human retinal pigment epithelial cells. PLoS One 8, e59603 (2013)

16. Howell JC, Chun E, Farrell AN, Hur EY, Caroti CM, Iuvone PM, Haque R: Global microRNA expression profiling: Curcumin (diferuloylmethane) alters oxidative stress-responsive microRNAs in human ARPE-19 cells. Mol. Vis. 19, 544-560 (2013)

17. Keane PA, de Salvo G, Sim DA, Goverdhan S, Agrawal R, Tufail A: Strategies for improving early detection and diagnosis of neovascular age-related macular degeneration. Clin. Ophthalmol. 9, 353-366 (2015)

18. King A, Gottlieb E, Brooks DG, Murphy MP, Dunaief JL: Mitochondria-derived reactive oxygen species mediate blue light-induced death of retinal pigment epithelial cells. Photochem. Photobiol. 79, 470-475 (2004)

19. Labunskyy VM, Gladyshev VN: Role of reactive oxygen species-mediated signaling in aging. Antioxid. Redox Signal. 19, 1362-1372 (2013)

20. Lawrence RA, Burk RF: Glutathione peroxidase activity in selenium-deficient rat liver. Biochem. Biophys. Res. Commun. 71, 952-958 (1976)

21. Liang FQ, Godley BF: Oxidative stress-induced mitochondrial DNA damage in human retinal pigment epithelial cells: A possible mechanism for RPE aging and age-related macular degeneration. Exp. Eye Res. 76, 397-403 (2003)

22. Liang FQ, Green L, Wang C, Alssadi R, Godley BF: Melatonin protects human retinal pigment epithelial (RPE) cells against oxidative stress. Exp. Eye Res. 78, 1069-1075 (2004)

23. Lipovsky A, Gedanken A, Lubart R: Visible light-induced antibacterial activity of metaloxide nanoparticles. Photomed. Laser Surg. 31, 526-530 (2013)

24. Lowry OH, Rosenbrough NJ, Farr AL, Randall RJ: Protein measurement with the folin phenol reagent. J. Biol. Chem. 193, 265-275 (1951)

25. Ma W, Lee SE, Guo J, Qu W, Hudson BI, Schmidt AM, Barile GR: RAGE ligand upregulation of VEGF secretion in ARPE-19 cells. Invest. Ophthalmol. Vis. Sci. 48, 1355-1361 (2007)

26. Placer ZA, Cushman LL, Johnson BC: Estimation of product of lipid peroxidation (malonyl dialdehyde) in biochemical systems. Anal. Biochem. 16, 359-364 (1966)

27. Rao RV, Ellerby HM, Bredesen DE: Coupling endoplasmic reticulum stress to the cell death program. Cell Death Differ. 11, 372-380 (2004)

28. Rasoulinejad SA, Zarghami A, Hosseini SR, Rajaee N, Rasoulinejad SE, Mikaniki E: Prevalence of age-related macular degeneration among the elderly. Caspian J. Intern. Med. 6, 141-147 (2015)

29. Roy SS, Hajnoczky G: Fluorometric methods for detection of mitochondrial membrane permeabilization in apoptosis. Methods Mol. Biol. 559, 173-190 (2009)

30. Sanderson MJ, Charles AC, Boitano S, Dirksen ER: Mechanisms and function of intercellular calcium signaling. Mol. Cell. Endocrinol. 98, 173-187 (1994)

31. Sedlak J, Lindsay RH: Estimation of total, protein-bound, and nonprotein sulfhydryl groups in tissue with Ellman's reagent. Anal. Biochem. 25, 192-205 (1968)

32. Singh RP, Sears JE: Retinal pigment epithelial tears after pegaptanib injection for exudative age-related macular degeneration. Am. J. Ophthalmol. 142, 160-162 (2006)

33. Uguz AC, Cig B, Espino J, Bejarano I, Naziroglu M, Rodriguez AB, Pariente JA: Melatonin potentiates chemotherapy-induced cytotoxicity and apoptosis in rat pancreatic tumor cells. J. Pineal Res. 53, 91-98 (2012)

34. Uguz AC, Naziroglu M: Effects of selenium on calcium signaling and apoptosis in rat dorsal root ganglion neurons induced by oxidative stress. Neurochem. Res. 37, 1631-1638 (2012) 
35. Uguz AC, Naziroglu M, Espino J, Bejarano I, Gonzalez D, Rodriguez AB, Pariente JA: Selenium modulates oxidative stress-induced cell apoptosis in human myeloid HL-60 cells through regulation of calcium release and caspase-3 and -9 activities. J. Membr. Biol. 232, 15-23 (2009)

36. Vainio I, Abu Khamidakh A, Paci M, Skottman H, Juuti-Uusitalo K, Hyttinen J, Nymark S: Computational model of $\mathrm{Ca}^{2+}$ wave propagation in human retinal pigment epithelial ARPE-19 cells. PLoS One 10, e0128434 (2015)

37. Wang LL, Sun Y, Huang K, Zheng L: Curcumin, a potential therapeutic candidate for retinal diseases. Mol. Nutr. Food Res. 57, 1557-1568 (2013)

38. Wenzel A, Grimm C, Marti A, Kueng-Hitz N, Hafezi F, Niemeyer G, Reme CE: C-fos controls the "private pathway" of light-induced apoptosis of retinal photoreceptors. J. Neurosci. 20, 81-88 (2000)

39. Woo JM, Shin DY, Lee SJ, Joe Y, Zheng M, Yim JH, Callaway Z, Chung HT: Curcumin protects retinal pigment epithelial cells against oxidative stress via induction of heme oxygenase-1 expression and reduction of reactive oxygen. Mol. Vis. 18, 901-908 (2012)

40. Zhu W, Wu Y, Meng YF, Wang JY, Xu M, Tao JJ, Lu J: Effect of curcumin on aging retinal pigment epithelial cells. Drug Des. Devel. Ther. 9, 5337-5344 (2015) 